\title{
A Damage Constitutive Model for a Rock under Compression after Freeze-Thaw Cycles Based on the Micromechanics
}

\author{
Hongyan Liu $\left(\mathbb{D},{ }^{1,2}\right.$ Xiaochen Zhang $\mathbb{D}^{3}$, and Xidong Yan $\mathbb{D}^{4}$ \\ ${ }^{1}$ College of Engineering \& Technology, China University of Geosciences (Beijing), Beijing 100083, China \\ ${ }^{2}$ Key Laboratory of Deep Geodrilling Technology of Ministry of Natural Resources, Beijing 100083, China \\ ${ }^{3}$ School of Safety Engineering, North China Institute of Science and Technology, Beijing 101601, China \\ ${ }^{4}$ RIOH Transport Consultants Ltd, Beijing 100088, China
}

Correspondence should be addressed to Hongyan Liu; lhyan1204@126.com

Received 12 May 2021; Accepted 8 July 2021; Published 23 July 2021

Academic Editor: Yu Wang

Copyright (c) 2021 Hongyan Liu et al. This is an open access article distributed under the Creative Commons Attribution License, which permits unrestricted use, distribution, and reproduction in any medium, provided the original work is properly cited.

\begin{abstract}
The freeze-thaw cycles will cause continuous damage to the rock, which is much related to the microcrack length, rock permeability, and frost heaving pressure. However, the failure mechanism of the rock under compression after freeze-thaw cycles is not very clear; therefore, it is studied with the damage theory here. First of all, according to the hydraulic pressure theory, the relationship between the frost heaving pressure and the microcrack propagation length in one single microcrack is established based on the elastoplastic mechanics and fracture theory. Second, by assuming the total strain of the rock under compression is comprised of the initial damage strain, elastic strain, additional damage strain, and plastic damage strain, a constitutive model for a rock based on the deformation and propagation of the microcrack under compression after freeze-thaw cycles is established. Finally, the proposed model is verified with the test result. In all, the proposed model can perfectly reflect the deterioration of the rock mechanical behavior under compression after the freeze-thaw cycles.
\end{abstract}

\section{Introduction}

Rock deterioration under freeze-thaw cycles is a hot issue in many engineering projects in cold regions. This deterioration proceeds with the freeze-thaw cycles, and the rock will gradually lose its stiffness and strength.

Water in the microcrack is assumed to be the key factor leading to the rock deterioration under freeze-thaw cycles. The deterioration mechanism of the porous media under freeze-thaw cycles was firstly described by Powers [1]. According to his theory, the frost heaving pressure will be generated by $9 \%$ volume expansion when water in the closed microcrack freezes into ice. It will make the microcrack propagate and cause damage to the rock. Thereafter, lots of laboratory tests have been done by many researchers, for instance, Altindag et al. [2], Momeni et al. [3], Nicholson and Nicholson [4], Zhang et al. [5], Wang et al. [6], Tounsi et al. [7], and Tang et al. [8]. All these results indicated that with the increasing number of freeze-thaw cycles, rock will deteriorate and degrade to some degree in terms of the compressive strength, elastic modulus, mass density, and so on.

No, many research works have been done in this field. Neaupane and Yamabeb [9] proposed a nonlinear elastoplastic constitutive relationship and a two-dimensional (plane stress) numerical modeling on the basis of the finite element method. With the continuum mechanics, Exadaktylos [10] established a coupled model for the saturated porous rocks under freeze-thaw cycles which can be used for analyzing the preliminary thawing experiments on the porous sandstone. According to the freeze-thaw cyclic fatigue tests on sandstone and shale, Tang et al. [8] assumed that the rock damage process included two coupled parts, e.g., the damage induced by the freeze-thaw cycles and the damage evolution caused by stress erosion. And then, a frost damage constitutive model is accordingly established. Based on the mass conservation law, energy conservation law, and the principle of static equilibrium, Kang et al. [11] studied the thermohydro-mechanical coupling mechanism and then proposed 
a new THM (thermo-hydro-mechanical) coupling model by considering phase change effect, in which the water migration caused by segregation potential and temperature gradient is described. By considering the coupling effects among fluid flow, heat transfer, crystallization, and deformation in porous media, $\mathrm{Wu}$ et al. [12] established a thermo-hydrosalt-mechanical coupled model for fully saturated porous media with phase change. From the viewpoint of the energy conservation law, mass conservation law, and the principle of static equilibrium considering water/ice phase change, Huang et al. [13] set up a fully coupled THM model and verified its validity with the laboratory test. Based on a microstructure-based random finite element model for the frozen soil, Dong and Yu [14] established a holistic model to simulate the temperature, stress, and deformation in frozen soil and implement a model to simulate frost heave and stress on water pipelines. In order to consider the migration of unfrozen water during freezing, Wang et al. [15] proposed a general thermo-mechanical-water migration coupled constitutive model to model mechanical degradation of rocks subjected to freeze-thaw cycles. Fan et al. [16] established a universal damage constitutive model under freeze-thaw and loading conditions based on the statistical damage constitutive model. Meanwhile, it can be seen that plasticity theory $[17,18]$ is often adopted to describe the nonlinear mechanical behavior of rock-like materials under freeze-thaw cycles.

Rock properties including the microcrack size distribution and permeability also have significant influence on rock mass mechanical behavior [19-22]. Hori and Moriniro [23] treated the shape of the microcrack as an ellipse in rock and set up a micromechanical model for the microscopic process. Although they assumed that the rock damage was induced by the microcrack propagation due to the water freezing and movement, they did not discuss the influence of microcrack distribution and permeability on rock deterioration. Therefore, the main objective of this research is to present an elastoplastic damage model for the rock with random distribution of the microcrack and the plastic yield criterion of the homogeneous medium combined with the micromechanical damage model to simulate the rock plastic deformation. The total strain of the rock is assumed to be comprised of initial damage strain, elastic strain, additional damage strain, and plastic damage strain [24], where the initial damage strain caused by the freeze-thaw cycles is calculated by the initial compliance matrix which is the function of freeze-thaw cycles. Meanwhile, the Drucker-Prager criterion is adopted to describe the plastic behavior of rock under compression, in which the microcrack radius is assumed to obey an exponential law [25]. Finally, the validity of the proposed model is verified with the experiment results.

\section{Propagation of One Single Microcrack under Frost Heaving Pressure}

2.1. The Relationship between the Microcrack Propagation Length and Ice Pressure in One Single Microcrack. Figure 1 illustrates a two-dimensional propagation model for one single microcrack under the frost heaving pressure. The microcrack is an ellipse, and its propagation under the frost

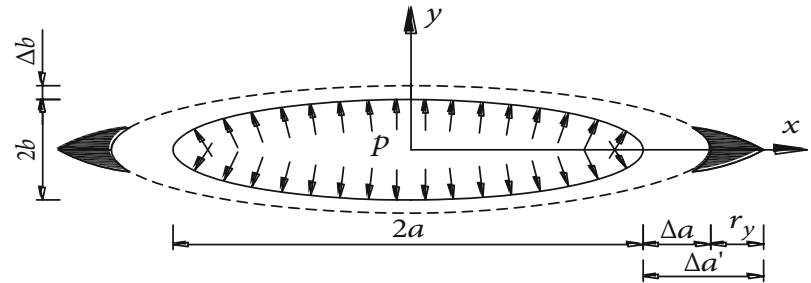

FIgURE 1: The microcrack propagation model under the frost heaving pressure. $2 a$ and $2 b$ are the length and width of the microcrack, respectively. $\triangle a$ and $\triangle b$ are the propagation length of the microcrack along two directions, respectively. $r_{y}$ is the length of the plastic zone near the microcrack tip. $\Delta a^{\prime}$ is the equivalent propagation length of the microcrack.

heaving pressure will lead to the rock damage. When freezing, the frost heaving pressure $p$ acts on the inner wall of the microcrack normally and evenly.

The following assumptions are made in this study: (1) the microcrack is always elliptical during the whole freeze-thaw cycles. That is to say, the shape of the microcrack is the same; only its size changes; (2) the rock particle is assumed to be unchanged; (3) the microcrack is always saturated, and the microcrack propagation obeys the linear elastic fracture mechanics; and (4) the propagation process of the microcrack is stable.

Water will change into ice with the volume expansion when temperature decreases to a certain degree. But because of the constraint of the microcrack wall, the stress induced by the ice volume expansion will act on the microcrack inner wall which will produce the elastic strain energy in the rock. When the stress intensity factor $K_{\mathrm{I}}$ is larger than the rock fracture toughness $K_{\mathrm{IC}}$, the microcrack will propagate, which will lead to the release of the elastic strain energy. According to the Griffith energy balance theory, there is

$$
W=E-U
$$

where $W, E$, are $U$ are work done by the frost heaving pressure, elastic strain energy stored in the rock, and the reduced total potential energy of the whole system, respectively.

Assume the elastic strain energy releases completely during the microcrack propagation, Equation (1) can be written into

$$
W=-U
$$

The work $W$ done by the frost heaving pressure on the inner wall of the microcrack is expressed as

$$
W=2 \times(p \times 2 a \times \Delta b)=4 p a \Delta b,
$$

where $p$ is the frost heaving pressure, $\Delta b$ is the microcrack opening displacement increment, shown in Figure 1.

The reduced total potential energy $U$ of the whole system in Equation (2) can be expressed as

$$
U=-2 G \times \Delta a,
$$


where $\triangle a$ is the microcrack propagation length and $G$ is the microcrack Griffith energy release rate.

There is a relationship between the volume of water and that of the ice [26]. Without considering the constraint of the microcrack wall, we assume the ice expansion volume is $\triangle V_{\mathrm{i}}$ under the free condition. However, in practice, the ice is loaded by the stress $p$, and accordingly, the corresponding volumetric strain $\varepsilon_{\mathrm{v}}$ can be calculated:

$$
\varepsilon_{\mathrm{v}}=\frac{3\left(1-2 v_{\mathrm{i}}\right)}{E_{\mathrm{i}}} p
$$

where $E_{\mathrm{i}}$ and $v_{\mathrm{i}}$ are the ice elastic modulus and Poisson's ratio, and here, they are assumed to be $600 \mathrm{MPa}$ and 0.3 , respectively.

Then, the actual volume increment $\Delta V_{\mathrm{i}}^{\prime}$ is

$$
\Delta V_{\mathrm{i}}^{\prime}=\Delta V_{\mathrm{i}}-V_{\mathrm{i}} \varepsilon
$$

where $V_{\mathrm{i}}$ is the volume of water before freezing.

According to the relationship of the water volume before and after the phase change, there is

$$
\pi a b+\Delta V_{\mathrm{i}}^{\prime}=\pi(a+\Delta a)(b+\Delta b) .
$$

The microcrack propagation length can be obtained by combining Equations(3), (4), (6), and (7)

$$
A(\Delta a)^{2}+B(\Delta a)+C=0
$$

where $A=\pi G, B=\pi(2 p a b+a G)$, and $C=-2 \Delta V_{\mathrm{i}}^{\prime} p a$.

Solving Equation (8) yields

$$
\Delta a=\frac{-(2 a b p+a G) \pi+\sqrt{(2 a b p+a G)^{2} \pi^{2}+8 G p a \times \Delta V_{\mathrm{i}}^{\prime}}}{2 G \pi} .
$$

For the rock especially the soft rock, the plastic zone will be formed near the microcrack tip when the microcrack wall is loaded by the frost heaving pressure. So, in order to satisfy the requirement of the linear elastic fracture mechanics, it is necessary to deal with the plastic zone near the microcrack tip with the equivalent method. The plastic region reduces the stiffness of the rock which is equivalent to a longer microcrack. The equivalent propagation length $a^{\prime}$ of the microcrack is [27]

$$
a^{\prime}=a+r_{y}
$$

where $a$ is the original microcrack length and $r_{y}$ is the length of the plastic zone near the microcrack tip shown in Figure 1, which can be expressed as for a plane stress issue [27].

$$
r_{y}=\frac{1}{2 \pi}\left(\frac{K_{\mathrm{I}}}{\sigma_{\mathrm{s}}}\right)^{2}
$$

where $\sigma_{s}$ is the rock yield strength and $K_{\mathrm{I}}$ is the first stress intensity factor at the microcrack tip.

So after amendment, the actual propagation length $\Delta a^{\prime}$ of the microcrack shown in Figure 1 is

$$
\Delta a^{\prime}=\Delta a+r_{y}
$$

The shape of the microcrack after propagation is shown as the dotted line in Figure 1.

After $m$ freeze-thaw cycles, the microcrack half-length $a_{m}$ is

$$
a_{m}=a_{m-1}+\frac{-\left(2 a_{m-1} b p+a_{m-1} G\right) \pi+\sqrt{\left(2 a_{m-1} b p+a_{m-1} G\right)^{2} \pi^{2}+8 G p a_{m-1} \times \Delta V_{\mathrm{i}}^{\prime}}}{2 G \pi}
$$

The microcrack propagation corresponds to the rock damage, and accordingly, the rock elastic modulus and compressive strength will also decrease.

2.2. The Frost Heaving Pressure. According to Walder and Hallet [28], the frost heaving pressure $p_{\mathrm{i}}$ is related to the duration time of the low temperature, the value of temperature, the volume of ice and water, and flow resistance, which can be calculated by

$$
p_{\mathrm{i}}(t)=\frac{L\left(-T_{\mathrm{c}}\right)}{v_{\mathrm{s}} T_{\mathrm{a}}}\left(1-e^{-(t / \tau)}\right)+p_{0} e^{-(t / \tau)}
$$

where the characteristic time $\tau$ is [28]

$$
\tau=\left(\frac{8}{3 \pi}\right)\left(\frac{1-v}{\mu}\right)\left(\frac{g a v_{\mathrm{L}}}{v_{\mathrm{s}}^{2}}\right) R_{\mathrm{f}}
$$

where $p_{\mathrm{i}}(t)$ is the frost heaving pressure of ice at time $t$; $L($ $\left.-T_{\mathrm{c}}\right) / \nu_{\mathrm{s}} T_{\mathrm{a}}=1.1 \mathrm{MPa} /{ }^{\circ} \mathrm{C} \times\left(-T_{\mathrm{c}}\right) . L\left(-T_{\mathrm{c}}\right)$ is the fusion heat of ice at $T=T_{\mathrm{c}}, \mathrm{kJ} / \mathrm{mol} ; v_{\mathrm{s}}$ and $v_{\mathrm{L}}$ are the relative volume of ice and water, respectively; when $T<-1^{\circ} \mathrm{C}, v_{\mathrm{L}}=0.07$ and $v_{\mathrm{S}}$ $=0.93$ [29]; $T_{\mathrm{a}}$ is the absolute temperature, $273.15 \mathrm{~K} ; p_{0}$ is the initial frost heaving pressure, and according to the experiment result, it is $2 \mathrm{MPa}$; $v$ is the rock Poisson ratio; $\mu$ is the 


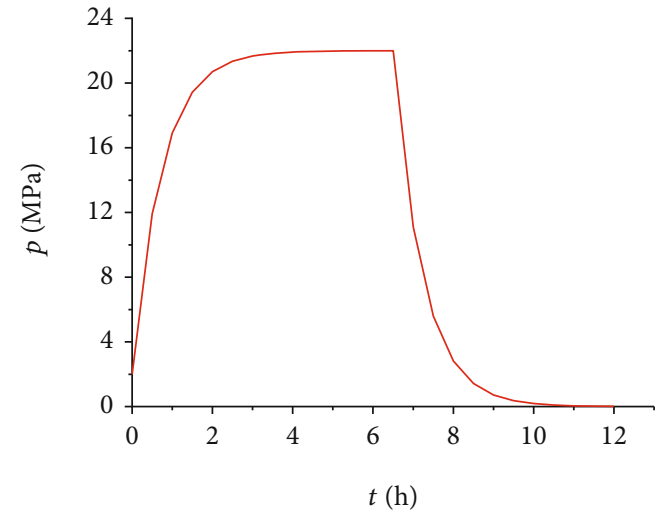

FIGURE 2: Variation of the frost heaving pressure with time during one freeze-thaw cycle.

rock shear modulus, $\mathrm{MPa} ; R_{\mathrm{f}}$ is the flow resistance, $\mathrm{Pa} \cdot \mathrm{s} / \mathrm{m} ; g$ is the gravitational acceleration, $\mathrm{m} / \mathrm{s}^{2} ; a$ is the microcrack half-length. Here, the freezing and thawing temperatures are adopted to be $-20^{\circ} \mathrm{C}$ and $20^{\circ} \mathrm{C}$, respectively. The time of one freeze-thaw cycle is $12 \mathrm{~h}$. The detailed calculation method of $R_{\mathrm{f}}$ has been introduced by Walder and Hallet [28].

Therefore, the variation of the frost heaving pressure with time is shown in Figure 2.

The work done by the frost heaving pressure along the microcrack inner wall for one freeze-thaw cycle is

$$
W=\int_{0}^{t_{\mathrm{i}}} 4 a p_{\mathrm{i}}(t) \frac{\Delta b}{t_{\mathrm{i}}} d t=4 a \frac{\Delta b}{t_{\mathrm{i}}} \int_{0}^{t_{\mathrm{i}}} p_{\mathrm{i}}(t) d t
$$

where $t_{\mathrm{i}}=43200 s$ and $p_{\mathrm{i}}(t)$ can be solved with Equation (14).

\section{Establishment of the Rock Constitutive Model under Compression after Freeze- Thaw Cycles}

3.1. Establishment of the Rock Constitutive Model. It is assumed that the water/ice phase change in freeze-thaw condition is the main reason leading to rock deterioration. The frost heaving pressure is generated by $9 \%$ volume expansion of freezing water in closed microcrack. The pressure makes the microcrack propagate and when the temperature rises, the melt water will go into the newly formed microcracks. The repeated freeze-thaw cycles cause continuous damage to the rock. Based on this viewpoint, the propagation of one single microcrack under the frost heaving pressure is studied, and the relationship between the propagation length of the microcrack and the frost heaving pressure is obtained. Because new damage continuously occurs under freezethaw cycles, the elastoplastic theory is adopted to study the rock damage mechanical behavior, and finally, a new constitutive model for a rock based on the deformation and propagation of microcracks under compression after freeze-thaw cycles is proposed.

3.2. Strain Decomposition. In this proposed model, the total strain of the rock under compression can be decomposed into the following four components such as the initial dam- age strain, elastic strain, plastic strain, and additional damage strain induced by the microcrack propagation. It can be expressed as

$$
\varepsilon=\varepsilon_{\mathrm{d}}+\varepsilon_{\mathrm{e}}+\varepsilon_{\mathrm{da}}+\varepsilon_{\mathrm{p}}
$$

where $\varepsilon$ is the total strain, $\varepsilon_{\mathrm{d}}$ is the initial damage strain, $\varepsilon_{\mathrm{e}}$ is the elastic strain, $\varepsilon_{\mathrm{da}}$ is the additional damage strain, and $\varepsilon_{\mathrm{p}}$ is the plastic strain. Their calculation methods are discussed below.

3.2.1. Initial Damage Strain Induced by Freeze-Thaw Cycles. The initial damage strain induced by freeze-thaw cycles is

$$
\left[\boldsymbol{\varepsilon}_{\mathrm{d}}\right]=\left[\mathbf{C}_{\mathrm{d}}\right][\boldsymbol{\sigma}],
$$

where $\left[C_{\mathrm{d}}\right]$ is the initial damage compliance matrix.

Assume the half-length of the $i^{\text {th }}$ microcrack becomes $a_{m}$ after $m$ freeze-thaw cycles. $\alpha_{i}$ is the orientation of the $i^{\text {th }}$ microcrack; then, the initial damage compliance matrix due to one single microcrack is given by [25]

$$
[\mathbf{C}]=\left[\mathbf{C}_{0}\right]+\left(\left[\mathbf{A}_{\mathbf{i}}\right]^{-1}\right)^{T}\left[\Delta \mathbf{C}_{\mathbf{i}}\right]\left[\mathbf{A}_{\mathbf{i}}\right]^{-1},
$$

where $\left[C_{0}\right]$ is the elastic compliance matrix, $\left[A_{\mathrm{i}}\right]$ is the transformation matrix, and $\left[A_{\mathrm{i}}\right]^{-1}$ is its inverse matrix.

$$
\begin{gathered}
{\left[\mathbf{A}_{\mathrm{i}}\right]=\left[\begin{array}{ccc}
\cos ^{2} \alpha_{\mathrm{i}} & \sin ^{2} \alpha_{\mathrm{i}} & -\sin 2 \alpha_{\mathrm{i}} \\
\sin ^{2} \alpha_{\mathrm{i}} & \cos ^{2} \alpha_{\mathrm{i}} & \sin 2 \alpha_{\mathrm{i}} \\
\frac{1}{2} \sin 2 \alpha_{\mathrm{i}} & -\frac{1}{2} \sin 2 \alpha_{\mathrm{i}} & \cos 2 \alpha_{\mathrm{i}}
\end{array}\right],} \\
{\left[\mathbf{A}_{\mathrm{i}}\right]^{-1}=\left[\begin{array}{ccc}
\cos ^{2} \alpha_{\mathrm{i}} & \sin ^{2} \alpha_{\mathrm{i}} & \sin 2 \alpha_{\mathrm{i}} \\
\sin ^{2} \alpha_{\mathrm{i}} & \cos ^{2} \alpha_{\mathrm{i}} & -\sin 2 \alpha_{\mathrm{i}} \\
\frac{1}{2} \sin 2 \alpha_{\mathrm{i}} & -\frac{1}{2} \sin 2 \alpha_{\mathrm{i}} & \cos 2 \alpha_{\mathrm{i}}
\end{array}\right],} \\
{\left[\Delta \mathbf{C}_{\mathrm{i}}\right]=\left[\begin{array}{ccc}
0 & 0 & 0 \\
0 & \frac{C_{\mathrm{n}}^{i} a_{m}^{i}}{K_{\mathrm{n}}^{i} 2 d h} & 0 \\
0 & 0 & \frac{C_{\mathrm{s}}^{i} a_{m}^{i}}{K_{\mathrm{s}}^{i} 2 d h}
\end{array}\right]}
\end{gathered}
$$

where $C_{\mathrm{n}}^{i}, C_{\mathrm{s}}^{i}, K_{\mathrm{n}}^{i}$, and $K_{\mathrm{s}}^{i}$ are the compression transferring coefficient, shear transferring coefficient, normal stiffness, and shear stiffness of the $i^{\text {th }}$ crack, respectively. $d$ and $h$ are width and height of the rock sample, respectively.

The total compliance matrix including $N$ microcracks whose half-length $a_{m}$ is

$$
[\mathbf{C}]=\left[\mathbf{C}_{0}\right]+\sum_{i=1}^{N}\left(\left[\mathbf{A}_{\mathrm{i}}\right]^{-1}\right)^{T}\left[\Delta \mathbf{C}_{\mathrm{i}}\right]\left[\mathbf{A}_{\mathbf{i}}\right]^{-1} .
$$

The orientation and size of the microcracks in the rock are assumed to be random, which can be expressed with a 
probability density function $\rho(a, \alpha)=\rho(a) \rho(\alpha)$. According to the distribution law of the microcrack, its orientation and size satisfy the following normalization condition [30]:

$$
\int_{a_{\min }}^{a_{\max }} \rho(a) d a \int_{0}^{\pi / 2} \rho(\alpha) \sin \alpha d \alpha=1
$$

Assume the total number of the microcracks is $N_{\mathrm{c}}$, and then, the number $N$ of the microcracks with half-length of a can be expressed as

$$
N=N_{\mathrm{c}} \int_{a_{\min }}^{a} \rho(a) d a
$$

Assume the orientation of the microcrack evenly distributes in all directions [31], and according to the definition of the density function, $\rho(\alpha)=1$ is obtained. Therefore, the total compliance matrix including all microcracks is

$$
[C]=\left[C_{0}\right]+N_{\mathrm{c}} \int_{a_{\min }}^{a_{\max }}\left(\left[A_{i}\right]^{-1}\right)^{T}\left[\Delta C_{\mathrm{i}}\right]\left[A_{\mathrm{i}}\right]^{-1} \rho(a) d a \int_{0}^{\pi / 2} \sin \alpha d \alpha .
$$

With Equation (24), the initial damage compliance matrix for different freeze-thaw cycles can be calculated and then, the initial damage strain can be finally obtained.

3.2.2. Elastic Strain. For a plane stress issue, the elastic constitutive relationship of rock is [32]

$$
\left[\boldsymbol{\varepsilon}_{\mathrm{e}}\right]=\left[\mathbf{C}_{0}\right][\boldsymbol{\sigma}] \text {, }
$$

where $\left[\boldsymbol{\varepsilon}_{\mathrm{e}}\right]$ is the elastic strain matrix, $\left[\boldsymbol{\varepsilon}_{\mathrm{e}}\right]=\left[\varepsilon_{11} \varepsilon_{33} \varepsilon_{13}\right]^{T},[\boldsymbol{\sigma}]$ is the stress matrix, $[\boldsymbol{\sigma}]=\left[\begin{array}{lll}\sigma_{11} & \sigma_{33} & \sigma_{13}\end{array}\right]$, and $\left[\mathbf{C}_{0}\right]$ is the elastic compliance matrix,

$$
\left[\mathbf{C}_{0}\right]=\left[\begin{array}{ccc}
\frac{1}{E} & -\frac{v}{E} & 0 \\
-\frac{\nu}{E} & \frac{1}{E} & 0 \\
0 & 0 & \frac{1}{\mu}
\end{array}\right]
$$

where $E, \mu$, and $v$ are the rock elastic modulus, shear modulus, and Poisson ratio, respectively.

3.2.3. Additional Damage Strain due to Compression. Under compression, the microcrack will firstly close, and then, the friction occurs along the microcrack face. When the shear stress along the microcrack face is larger than the friction, the wing crack will initiate and propagate from the microcrack tip. The propagation of the microcrack will lead to the decrease in the rock elastic modulus, strength, and increase in the rock permeability. The sliding microcrack model under compression is shown in Figure 3.

After $m$ freeze-thaw cycles, the microcrack length becomes $a_{m}$, and for this moment, the first stress intensity

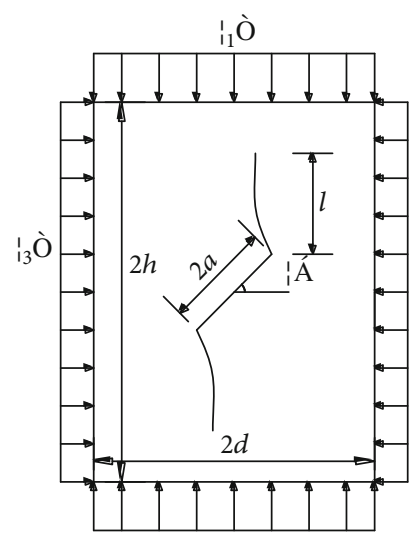

FIgURE 3: The sliding microcrack model under compression. $2 a$ and $\alpha$ are the length and dip angle of the microcrack, respectively. $l$ is the wing crack length. $2 h$ and $2 d$ are the height and width of the model, respectively.

factor $K_{\mathrm{I}}$ at the microcrack tip is $[31,33]$

$$
K_{\mathrm{I}}=\frac{2}{\sqrt{3}} \tau^{*} \sqrt{\pi a_{m}}
$$

where $\tau^{*}$ is the effective shear stress on the microcrack face, $\tau^{*}=\tau_{\mathrm{m}}-f \sigma_{\mathrm{m}}, \tau_{\mathrm{m}}$ and $\sigma_{\mathrm{m}}$ are the shear and normal stresses on the microcrack face, respectively, and $f$ is the friction coefficient of the microcrack face.

$$
\begin{gathered}
\tau_{\mathrm{m}}=\frac{\sigma_{1}-\sigma_{3}}{2} \sin 2 \alpha, \\
\sigma_{\mathrm{m}}=\frac{\sigma_{1}+\sigma_{3}}{2}-\frac{\sigma_{1}-\sigma_{3}}{2} \cos 2 \alpha .
\end{gathered}
$$

When $K_{I} \geq K_{\mathrm{IC}}$ ( $K_{\mathrm{IC}}$ is the rock fracture toughness), the microcrack begins to propagate, and the stress intensity factor $K_{\mathrm{I}}^{\mathrm{W}}$ at the wing crack tip is $[31,33]$.

$$
K_{\mathrm{I}}^{\mathrm{W}}=\frac{2 a \tau^{*} \cos \alpha}{\sqrt{\pi l}}-\sigma_{3} \sqrt{\pi l}
$$

where

$$
\tau^{*}=\frac{1}{2}\left[\left(\sigma_{1}-\sigma_{3}\right) \sin 2 \alpha-f\left(\sigma_{1}+\sigma_{3}+\left(\sigma_{1}-\sigma_{3}\right) \cos 2 \alpha\right)\right]
$$

The wing crack will stop propagating when $K_{I}^{\mathrm{W}} \leq K_{\mathrm{IC}}$, so $l$ can be calculated with Equation (29).

The additional damage of a rock is due to the wing crack propagation. According to Li and Lajtai [34], the 
macroscopic strain of a rock can be calculated.

$$
\begin{gathered}
\varepsilon_{1}^{*}=\frac{8 \lambda \chi \cos \alpha}{E}\left[\frac{2 \tau^{*} \cos \alpha}{\pi} \ln \frac{l}{a}-\sigma_{3}\left(\frac{l}{a}-1\right)\right], \\
\varepsilon_{3}^{*}=\frac{\chi}{E}\left[\begin{array}{c}
\frac{16 \tau^{*} \gamma \cos ^{2} \alpha}{\pi} \ln \frac{l}{a}+\sigma_{3} \pi\left(\frac{l^{2}}{a^{2}}-1\right) \\
-8 \cos \alpha\left(\frac{l}{a}-1\right)\left(\sigma_{3} \gamma+\tau^{*}\right)
\end{array}\right],
\end{gathered}
$$

where $\varepsilon_{1}^{*}$ and $\varepsilon_{3}^{*}$ are the strains along the vertical and horizontal directions, respectively; $\lambda=\sin \alpha \cos \alpha-f \cos ^{2} \alpha ; \gamma$ $=-\cos \alpha \sin \alpha-f \sin ^{2} \alpha$. $\chi$ is defined as the initial microcrack density and is expressed as $\chi=N a^{2} / V . N$ is the total number of the microcracks in a two-dimensional body of unit thickness whose volume is $V=2 h \times 2 d$.

Finally, the total rock strain due to compression considering the normalization condition is

$$
\begin{aligned}
\varepsilon_{1}= & N_{\mathrm{c}} \int_{a_{\min }}^{a_{\max }} \rho(a) d a \int_{0}^{\pi / 2} \rho(\alpha) \sin \alpha d \alpha \cdot \frac{8 \lambda \chi \cos \alpha}{E} \\
& \times\left[\frac{2 \tau^{*} \cos \alpha}{\pi} \ln \frac{l}{a}-\sigma_{3}\left(\frac{l}{a}-1\right)\right], \\
\varepsilon_{3}= & N_{\mathrm{c}} \int_{a_{\min }}^{a_{\max }} \rho(a) d a \int_{0}^{\pi / 2} \rho(\alpha) \sin \alpha d \alpha \cdot \frac{\chi}{E} \\
& \times\left[\frac{16 \tau^{*} \gamma \cos ^{2} \alpha}{\pi} \ln \frac{l}{a}+\sigma_{3} \pi\left(\frac{l^{2}}{a^{2}}-1\right)\right. \\
& \left.-8 \cos \alpha\left(\frac{l}{a}-1\right)\left(\sigma_{3} \gamma+\tau^{*}\right)\right] .
\end{aligned}
$$

3.2.4. The Plastic Strain due to Compression. The DruckerPrager model is adopted to describe the rock plastic behavior, whose yield function and plastic potential function are

$$
\begin{aligned}
& F(\sigma, \kappa)=\beta_{1} I_{1}+\sqrt{J_{2}}-\kappa, \\
& G(\sigma, \kappa)=\beta_{2} I_{1}+\sqrt{J_{2}}-\kappa
\end{aligned}
$$

where $I_{1}=\sigma_{1}+\sigma_{2}+\sigma_{3}, \quad J_{2}=(1 / 6)\left[\left(\sigma_{1}-\sigma_{2}\right)^{2}+\left(\sigma_{2}-\sigma_{3}\right)^{2}\right.$ $\left.+\left(\sigma_{3}-\sigma_{1}\right)^{2}\right], \beta_{1}=2 \sin \varphi / \sqrt{3}(3-\sin \varphi), \quad \beta_{2}=2 \sin \psi / \sqrt{3}($ $3-\sin \psi)$, and $\varphi$ and $\psi$ are the friction angle and dilation angle, respectively. $\kappa$ is the hardening function, which can be expressed as [35]

$$
\kappa=\sigma_{0}+a_{1} \lambda \exp \left(a_{2} I_{1}-a_{3} \lambda\right)
$$

where $a_{1}, a_{2}$, and $a_{3}$ are the constants which can be obtained by fitting with the uniaxial compressive stressstrain curve. $\sigma_{0}=6 c \cos \varphi / \sqrt{3}(3-\sin \varphi) ; c$ is the rock cohesion.

According to Tan et al. [36], the rock internal friction angle is basically the same, but the rock cohesion decreases

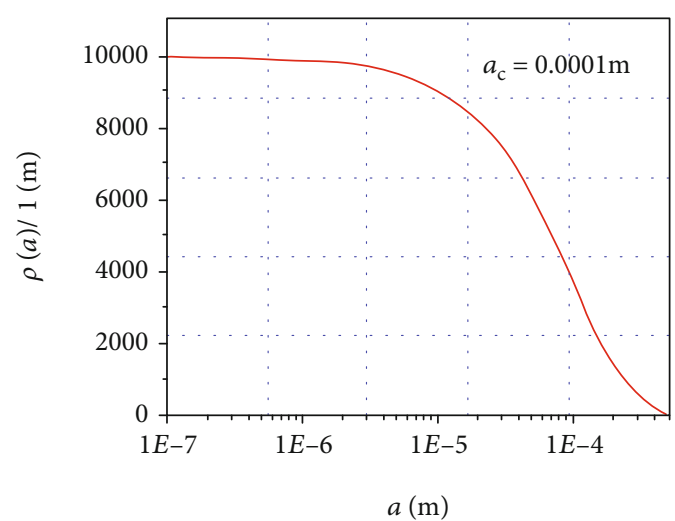

Figure 4: Probability density functions of the microcracks.

with the freeze-thaw cycles and obeys the following exponential function:

$$
c(m)=c_{0} e^{-0.072 m},
$$

where $c_{0}$ is the original cohesion strength (before freeze-thaw cycle) and $c(m)$ is the cohesion after the $m^{\text {th }}$ freeze-thaw cycle.

The plastic strain rate is

$$
\dot{\varepsilon}_{\mathrm{p}}=\dot{\lambda} \frac{\partial G}{\partial \sigma}
$$

where $\dot{\lambda}$ is a proportion coefficient.

3.2.5. The Number of the Microcracks in a Rock. The probability function [37] of the microcrack length can be expressed as

$$
\rho(a)= \begin{cases}-\frac{1}{a_{\mathrm{c}}} \exp \left(-\frac{a}{a_{\mathrm{c}}}\right), & a_{\mathrm{min}} \leq a \leq a_{\mathrm{max}} \\ 0, & \text { otherwise }\end{cases}
$$

where $a_{\mathrm{c}}$ is the characteristic length of the microcrack, $a_{\mathrm{c}}=$ $\int_{a_{\min }}^{a_{\max }} \rho(a) a d a . N_{\mathrm{c}}$ is the total number of the microcracks per unit volume, which is determined by the total volume of the microcrack, $V_{\mathrm{c}}=2 \pi b N_{\mathrm{c}} \int_{a_{\min }}^{a_{\max }} \rho(a) a^{2} d a$.

Finally, the curve of probability density function of the microcracks is shown in Figure 4.

According to the experiment result of Rostásy et al. [38], the total number of the microcracks basically remains the same after freeze-thaw cycles. The longer microcracks will propagate, while the shorter ones will close under the extrusion of other microcracks. Therefore, it is assumed that the total volume of the microcrack is the same during the freeze-thaw cycles and compression. So the total volume $V_{c}$ of the microcracks can be expressed with the rock void porosity $e$ and the total volume $V$ of the rock sample, namely, $V_{\mathrm{c}}=e V$. 


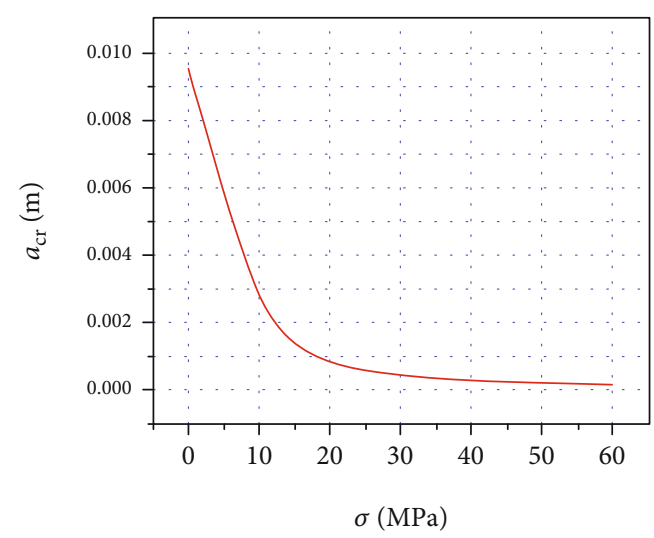

FIGURE 5: Relationship between the microcrack critical length and axial stress.

The first stress intensity factor $K_{\mathrm{I}}$ of the microcrack with different lengths at the same stress condition can be expressed as

$$
K_{\mathrm{I}}=\frac{2}{\sqrt{3}} \tau^{*} \sqrt{\pi a}
$$

Equation (38) can be changed into

$$
\left(\frac{\sqrt{3} K_{\mathrm{IC}}}{2 \tau^{*}}\right)^{2} \frac{1}{\pi}=a_{\mathrm{cr}}
$$

where $\quad \tau^{*}=(1 / 2)\left[\left(\sigma_{1}-\sigma_{3}\right) \sin 2 \varphi-f\left(\sigma_{1}+\sigma_{3}+\left(\sigma_{1}-\sigma_{3}\right)\right.\right.$ $\cos 2 \varphi)$ ] where $a_{\text {cr }}$ is the critical length of the microcrack which becomes active at the condition of $\sigma_{1}$ and $\sigma_{3}$ when $K_{I}=K_{\text {IC }}$.

As shown in Figure 5, the microcrack whose length is greater than $a_{\mathrm{cr}}$ will propagate.

The total number of microcracks that will be actually activated is given by $N=N_{\mathrm{c}} \int_{a_{\min }}^{a_{\max }} \rho(a) d a$, as shown in Figure 6.

3.2.6. The Numerical Algorithm of the Proposed Model. The calculation of the rock plastic strain at different times can be calculated with the semi-implicit return graphical algorithm [17], shown in Figure 7. The plastic variables $\boldsymbol{\sigma}_{n+1}, \boldsymbol{\varepsilon}_{n+1}^{p}, \kappa_{n+1}, r_{n+1}$, and $h_{n+1}$ at $t_{n+1}$ are determined by integration flow rule and hardening law and $\Delta \boldsymbol{\sigma}^{\text {tr }}, \sigma_{n}, \kappa_{n}$, $r_{n}=\partial F /\left.\partial \sigma\right|_{\sigma=\sigma_{n}}$, and $h_{n}=\partial \kappa /\left.\partial \lambda\right|_{\lambda=\lambda_{n}}$ at time $t_{n}$. The main steps are as follows:

(1) Update strain tensor, and calculate the elastic strain at time $t_{n+1}$

$$
\begin{gathered}
\boldsymbol{\varepsilon}_{n+1}=\boldsymbol{\varepsilon}_{n}+\Delta \boldsymbol{\varepsilon}, \\
\Delta \boldsymbol{\sigma}_{n+1}^{\mathrm{tr}}=\mathbf{C}^{-1}: \Delta \boldsymbol{\varepsilon},
\end{gathered}
$$

where $\mathbf{C}$ is the initial elastic compliance matrix including the initial damage compliance tensor caused by freeze-thaw and elastic compliance tensor.

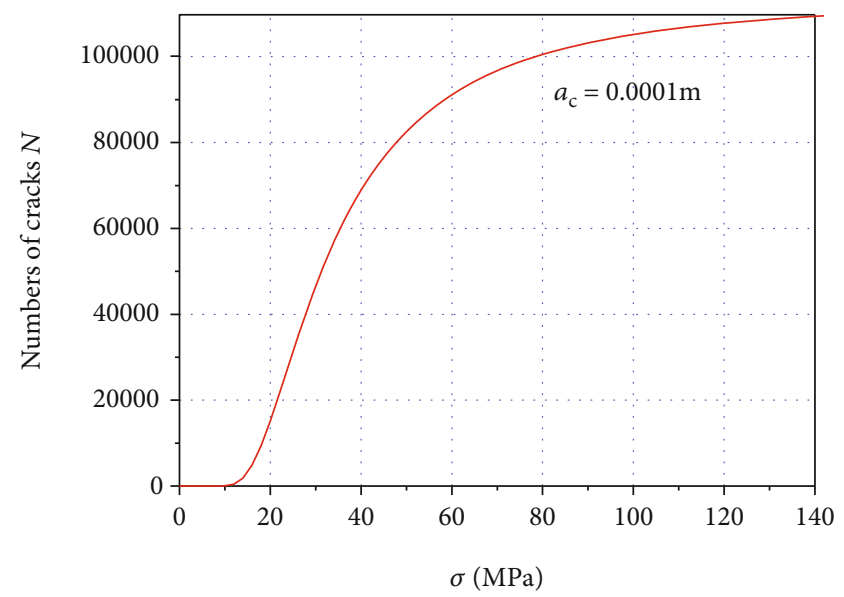

FIgURE 6: Relationship between the microcrack initiation number and axial stress.

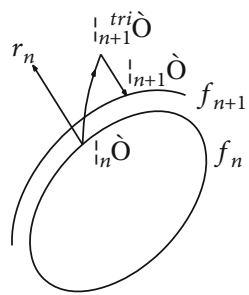

FIgURE 7: Graphic returns method of semi-implicit integration algorithm.

(2) Update stresses and plastic strain and hardening function $\kappa_{n+1}$

$$
\begin{gathered}
\boldsymbol{\varepsilon}_{n+1}^{p}=\boldsymbol{\varepsilon}_{n}^{p}+\Delta \lambda_{n+1} \mathbf{r}_{n}, \\
\kappa_{n+1}=\kappa_{n} \Delta \lambda_{n+1} h_{n} \\
\sigma_{n+1}=\boldsymbol{C}^{-1}:\left(\varepsilon_{n+1}-\boldsymbol{\varepsilon}_{n+1}^{p}\right) \\
F_{n+1}=F\left(\sigma_{n+1}, \kappa_{n+1}\right)=0
\end{gathered}
$$

where $r_{n}=\partial G /\left.\partial \sigma\right|_{\sigma=\sigma_{n}}$ and $h_{n}=\partial \kappa /\left.\partial \kappa\right|_{\lambda=\lambda_{n}}$.

Calculate the plastic internal variable $\Delta \lambda_{n+1}$ :

$$
a_{n+1}^{k}+C^{-1}: \Delta \sigma_{n+1}^{k}+\delta \lambda^{k} r_{n}=0
$$

$$
b_{n+1}^{k}-\Delta \kappa_{n+1}^{k}+\delta \lambda_{n+1}^{k} h_{n}=0,
$$

$$
F_{n+1}^{k}+F_{\sigma}^{k}: \Delta \sigma_{n+1}^{k}+F_{\kappa}^{k} \cdot \Delta \kappa_{n+1}^{k}=0
$$

$$
\left[\begin{array}{c}
\Delta \sigma \\
\Delta \kappa
\end{array}\right]=-\left[A^{(k)}\right]\left[\tilde{a}^{(k)}\right]-\delta \lambda^{(k)}\left[A^{(k)}\right]\left[\tilde{r}_{n}\right],
$$




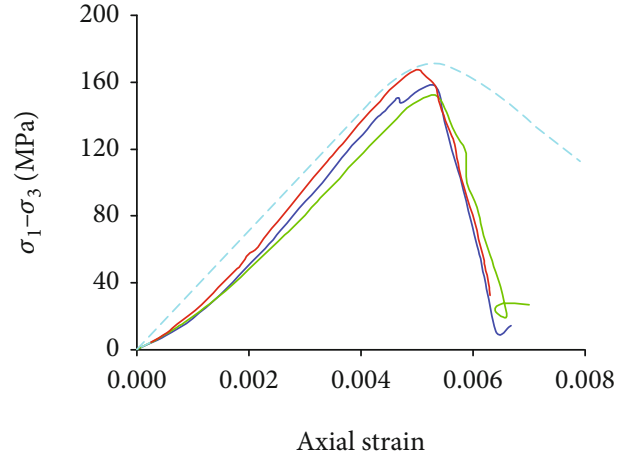

$m=0$ test result \#1

$m=0$ test result \#2

$-m=0$ test result \#3

- $m=0$ simulated with the proposed model

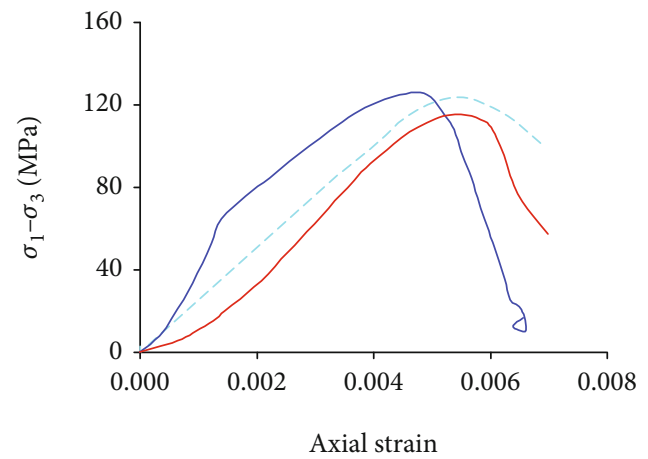

$m=50$ test result \#1

$m=50$ test result \#3

$m=50$ simulated with the proposed model

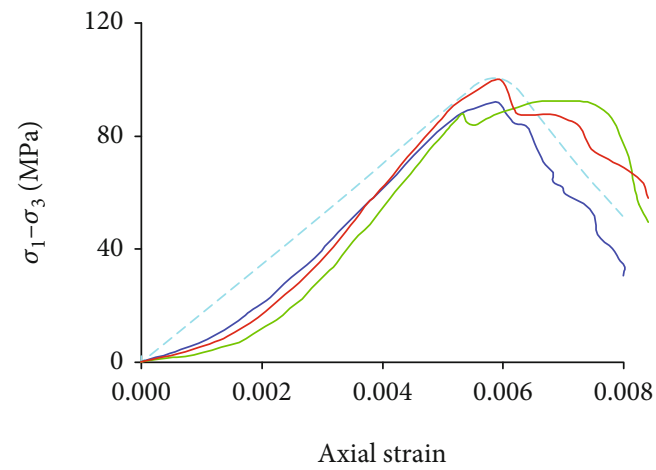

$m=100$ test result \#1

$m=100$ test result \#2

$m=100$ test result \#3

- - $m=100$ simulated with the proposed model

Figure 8: Comparison of the stress-strain relationships for triaxial compression tests with confining pressure $\sigma_{3}=5 \mathrm{MPa}$ by Tan et al. [36] and simulated with the proposed model. The predicted stressstrain relationships agree well with the tested ones.

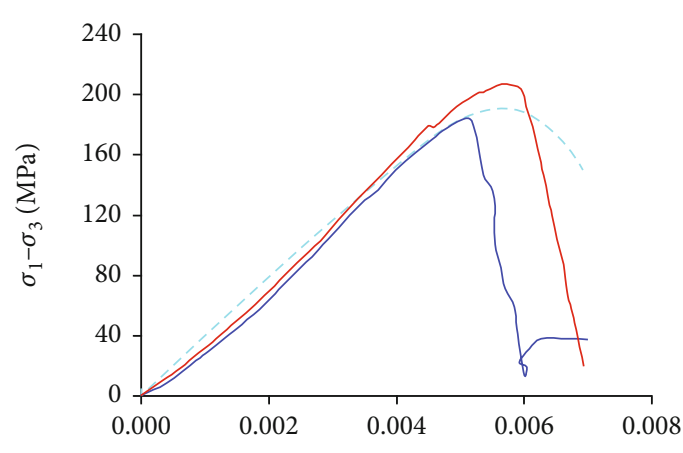

Axial strain

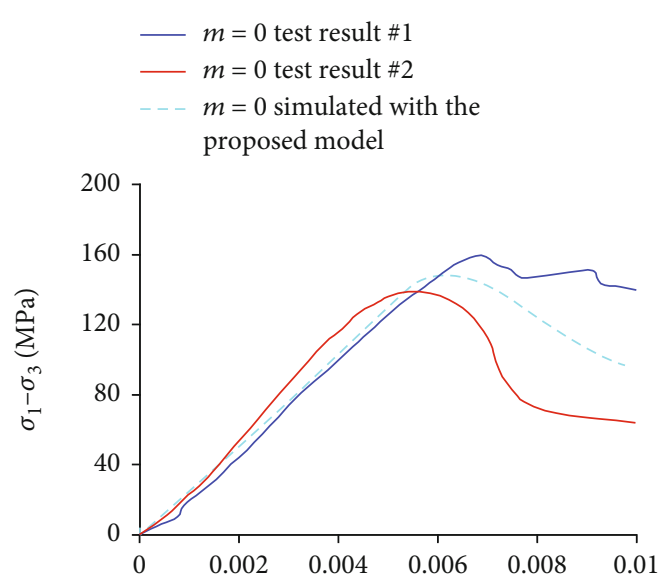

Axial strain
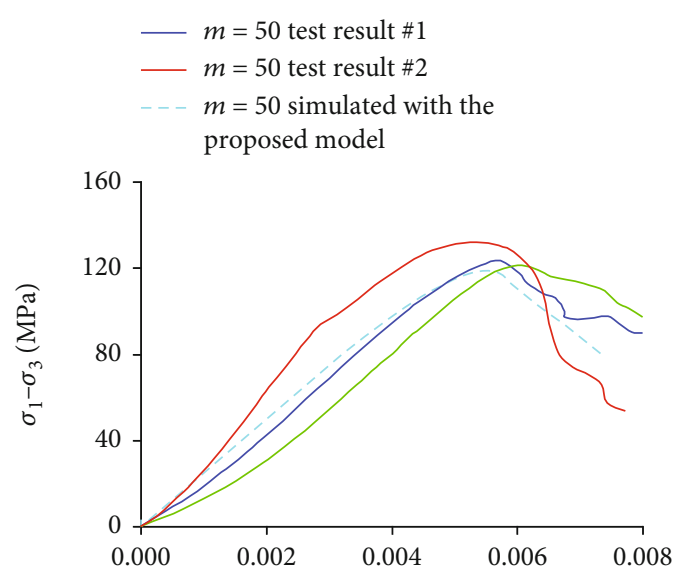

Axial strain

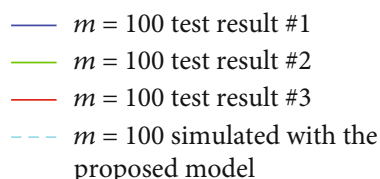

FIGURE 9: Comparison of the stress-strain relationships for triaxial compression tests with confining pressure $\sigma_{3}=10 \mathrm{MPa}$ by Tan et al. [36] and simulated with the proposed model. The predicted stress-strain relationships agree well with the tested ones. 
TABLE 1: The calculation parameters.

\begin{tabular}{lccccccccc}
\hline$E(\mathrm{GPa})$ & $v$ & $e$ & $c(\mathrm{MPa})$ & $a_{1}(\mathrm{MPa})$ & $a_{2}\left(\mathrm{MPa}^{-1}\right)$ & $a_{3}$ & $a_{\mathrm{c}}(\mathrm{m})$ & $a_{\min }(\mathrm{m})$ & $a_{\max }(\mathrm{m})$ \\
\hline 36.71 & 0.2 & 0.0067 & 27.43 & $5 e 9$ & $1 e-8$ & 100 & $1 e-4$ & $1 e-7$ & 0.0012 \\
\hline
\end{tabular}

where

$$
\begin{gathered}
{\left[A^{k}\right]=\left[\begin{array}{cc}
C & 0 \\
0 & -I
\end{array}\right],} \\
{\left[\tilde{a}^{(k)}\right]=\left[\begin{array}{l}
a^{k} \\
b^{k}
\end{array}\right]=\left[\begin{array}{l}
0 \\
0
\end{array}\right],} \\
{\left[\tilde{r}_{n}\right]=\left[\begin{array}{l}
r_{n} \\
h_{n}
\end{array}\right] .}
\end{gathered}
$$

$\delta \lambda^{(k)}$ can be obtained with Equation (45)

$$
\delta \lambda=\frac{F^{k}}{\partial F: A^{k}: \tilde{r}_{n}},
$$

where $[\partial F]=\left[\begin{array}{ll}F_{\sigma} & F_{\kappa}\end{array}\right]$.

$$
\Delta \lambda_{n+1}^{k+1}=\Delta \lambda_{n}^{k}+\delta \lambda^{k} .
$$

(3) Update $N_{n+1}$ which is the number of microcracks that begin propagating

At time $t_{n+1}$, the updated normal stress is $\sigma_{n+1}$, under which the critical initiation length $\left(a_{\mathrm{cr}}\right)_{n+1}$ of the microcrack is calculated by

$$
\left(a_{\mathrm{cr}}\right)_{n+1}=\frac{1}{\pi}\left(\frac{\sqrt{3} K_{\mathrm{IC}}}{2\left(\tau^{*}\right)_{n+1}}\right)^{2}
$$

where

$$
\begin{gathered}
\left(\tau^{*}\right)_{n+1}=\frac{1}{2}\left[\begin{array}{c}
\left(\left(\sigma_{1}\right)_{n+1}^{\mathrm{tr}}-\sigma_{3}\right) \sin 2 \varphi \\
-\mu\left(\left(\sigma_{1}\right)_{n+1}^{\mathrm{tr}}+\sigma_{3}+\left(\left(\sigma_{1}\right)_{n+1}^{\mathrm{tr}}-\sigma_{3}\right) \cos 2 \varphi\right)
\end{array}\right], \\
N_{n+1}=N_{\mathrm{c}} \int_{\left(a_{\mathrm{cr}}\right)_{n+1}}^{a_{\max }} \rho(a) d a .
\end{gathered}
$$

(4) Update the additional damage strain $\left(\boldsymbol{\varepsilon}_{\mathrm{ad}}\right)_{n+1}$

The additional damage strain matrix of $\boldsymbol{\varepsilon}_{\mathrm{ad}}$ can be expressed as

$$
\left[\boldsymbol{\varepsilon}_{\mathrm{ad}}\right]=\left[\begin{array}{lll}
\varepsilon_{1} & \varepsilon_{3} & 0
\end{array}\right] .
$$

Update the length of wing crack $l_{n+1}$

$$
K_{\mathrm{I}}^{\mathrm{W}}=\frac{2 a(\tau)_{n+1} \cos \varphi}{\sqrt{\pi l_{n+1}}}-\left(\sigma_{3}\right)_{n+1} \sqrt{\pi l_{n+1}},
$$

where $K_{\mathrm{I}}^{\mathrm{W}}=K_{\mathrm{IC}}$.

Update the additional strain

$$
\begin{aligned}
& \left(\varepsilon_{1}\right)_{n+1}=N_{n+1} \int_{\left(a_{\mathrm{cr}}\right)_{n+1}}^{a_{\max }} \rho(a) d a \int_{0}^{\pi / 2} \rho(\alpha) \sin \alpha d \alpha \cdot \frac{8 \lambda a \cos ^{2} \alpha}{E} \\
& \times\left[\frac{2\left(\tau^{*}\right)_{n+1} \cos \alpha}{\pi} \ln \frac{l_{n+1}}{a}-\sigma_{3}\left(\frac{l_{n+1}}{a}-1\right)\right], \\
& \left(\varepsilon_{3}\right)_{n+1}=N_{n+1} \int_{\left(a_{c r}\right)_{n+1}}^{a_{\max }} \rho(a) d a \int_{0}^{\pi / 2} \rho(\alpha) \sin \alpha d \alpha \cdot \frac{a^{2}}{E} \\
& \times\left[\begin{array}{c}
\frac{16\left(\tau^{*}\right)_{n+1} \gamma \cos ^{2} \alpha}{\pi} \ln \frac{l_{n+1}}{a}+\sigma_{3} \pi\left(\frac{\left(l_{n+1}\right)^{2}}{a^{2}}-1\right) \\
-8 \cos \varphi\left(\frac{l_{n+1}}{a}-1\right)\left(\sigma_{3} \gamma+\left(\tau^{*}\right)_{n+1}\right)
\end{array}\right] .
\end{aligned}
$$

(5) Update the stress

$$
\boldsymbol{\sigma}_{n+1}^{*}=\boldsymbol{\sigma}_{n+1}-\mathbf{C}^{-1}:\left(\boldsymbol{\varepsilon}_{\mathrm{ad}}\right)_{n+1}
$$

\section{Verification of the Proposed Model}

In order to verify the proposed model, the experiment by Tan et al. [36] is taken for an example. The rock type is granite, which is obtained from Galongla mountain in Tibet of China, where a highway tunnel passes through the mountain and it is very cold in winter. The tested samples are prepared as cylinders with $50 \mathrm{~mm}$ in diameter and $100 \mathrm{~mm}$ high. The compression tests with confining pressure $5 \mathrm{MPa}$ and $10 \mathrm{MPa}$ on the rock sample are done with a multifunction rock mechanics test machine, and the corresponding stress-strain curves are shown in Figures 8 and 9. The calculation parameters are shown in Table 1.

The characteristic length $a_{\mathrm{c}}$ of the microcrack under 0 , 50, and 100 freeze-thaw cycles is solved to be $0.1 \mathrm{~mm}$, $0.41 \mathrm{~mm}$ and $1.64 \mathrm{~mm}$, respectively, with Equation (13). According to the proposed model, the complete stressstrain curve of the rock under compression with confining pressure $\sigma_{3}=5 \mathrm{MPa} / 10 \mathrm{MPa}$ is shown in Figures 8 and 9 . 
It can be seen that the simulated stress-strain curves agree well with the tested ones especially when $\sigma_{3}=10 \mathrm{MPa}$. Meanwhile, with the increasing freeze-thaw cycles, both the climax strength and slope of the stress-strain curve decrease; that is to say, the rock compressive strength and elastic modulus both decrease. It indicates that the freeze-thaw cycles have much effect on the rock mechanical behavior.

\section{Conclusions}

(1) Based on the fracture mechanics, the calculation method of the microcrack propagation length induced by the freeze-thaw cycles is proposed. Meanwhile, the variation of the frost heaving pressure with time during one freeze-thaw cycle is also calculated

(2) In the framework of the fracture and damage mechanics, the total strain of the rock under compression after freeze-thaw cycles can be decomposed into the initial damage strain, elastic strain, plastic strain, and additional damage strain. And their calculation methods are discussed in detail. Finally, a constitutive model for a rock based on the deformation and propagation of microcracks under compression after freeze-thaw cycles is established

(3) By utilizing the semi-implicit algorithm, the stressstrain relationship of the proposed model is calculated. The comparison of the theoretical results of the proposed method and test ones shows that they agree well with each other. Overall, the proposed method provides a new way to simulate the mechanical behavior of a rock under compression after freeze-thaw cycles

\section{Data Availability}

All data generated or analyzed during this study are included in this manuscript.

\section{Conflicts of Interest}

The authors declare that there are no conflicts of interest regarding the publication of this paper.

\section{Acknowledgments}

This study is supported by the National Key Research and Development Plan of China (2019YFC1509701).

\section{References}

[1] T. C. Powers, "Freezing effect in concrete. Durability of concrete," in ACI SP47, pp. 1-11, American Concrete Institute, Detroit, Michigan, 1975.

[2] R. Altindag, I. S. Alyildiz, and T. Onargan, "Mechanical property degradation of ignimbrite subjected to recurrent freezethaw cycles," International Journal of Rock Mechanics and Mining Sciences, vol. 41, no. 6, pp. 1023-1028, 2004.
[3] A. Momeni, Y. Abdilor, G. R. Khanlari, M. Heidari, and A. A. Sepahi, "The effect of freeze-thaw cycles on physical and mechanical properties of granitoid hard rocks," Bulletin of Engineering Geology and the Environment, vol. 75, pp. 16491656, 2016.

[4] D. T. Nicholson and F. H. Nicholson, "Physical deterioration of sedimentary rocks subjected to experimental freeze-thaw weathering," Earth Surface Processes and Landforms, vol. 25, no. 12, pp. 1295-1307, 2000.

[5] J. Zhang, H. W. Deng, J. R. Deng, and B. Ke, "Development of energy-based brittleness index for sandstone subjected to freeze-thaw cycles and impact loads," IEEE Access, vol. 6, pp. 48522-48530, 2018.

[6] S. R. Wang, Y. L. Chen, J. Ni, M. D. Zhang, and H. Zhang, "Influence of freeze-thaw cycles on engineering properties of tonalite: examples from China," Advances in Civil Engineering, vol. 2019, Article ID 3418134, 12 pages, 2019.

[7] H. Tounsi, A. Rouabhi, E. Jahangir, and F. Guerin, "Mechanical behavior of frozen metapelite: laboratory investigation and constitutive modeling," Cold Regions Science and Technology, vol. 175, 2020.

[8] Z. C. Tang, L. Li, X. C. Wang, and J. P. Zou, "Influence of cyclic freezing-thawing treatment on shear behaviors of granite fracture under dried and saturated conditions," Cold Regions Science and Technology, vol. 181, p. 103192, 2021.

[9] K. M. Neaupane and T. Yamabe, "A fully coupled thermohydro-mechanical nonlinear model for a frozen medium," Computers and Geotechnics, vol. 28, no. 8, pp. 613-637, 2001.

[10] G. E. Exadaktylos, "Freezing-thawing model for soils and rocks," Journal of Materials in Civil Engineering, vol. 18, no. 2, pp. 241-249, 2006.

[11] Y. S. Kang, Q. S. Liu, and S. B. Huang, "A fully coupled thermo-hydro-mechanical model for rock mass under freezing/thawing condition," Cold Regions Science and Technology, vol. 95, pp. 19-26, 2013.

[12] D. Y. Wu, Y. M. Lai, and M. Zhang, "Thermo-hydro-saltmechanical coupled model for saturated porous media based on crystallization kinetics," Cold Regions Science and Technology, vol. 133, pp. 94-107, 2017.

[13] S. B. Huang, Q. S. Liu, A. Cheng, Y. Z. Liu, and G. F. Liu, “A fully coupled thermo-hydro-mechanical model including the determination of coupling parameters for freezing rock," International Journal of Rock Mechanics and Mining Sciences, vol. 103, pp. 205-214, 2018.

[14] S. Y. Dong and X. Yu, "Microstructure-based random finite element method simulation of frost heave: theory and implementation," Transportation Research Record, vol. 2672, no. 52, pp. 347-357, 2018.

[15] Z. Wang, Z. D. Zhu, and S. Zhu, "Thermo-mechanical-water migration coupled plastic constitutive model of rock subjected to freeze-thaw," Cold Regions Science and Technology, vol. 161, pp. 71-80, 2019.

[16] W. Fang, N. Jiang, and X. D. Luo, "Establishment of damage statistical constitutive model of loaded rock and method for determining its parameters under freeze-thaw condition," Cold Regions Science and Technology, vol. 160, pp. 31-38, 2019.

[17] J. C. Simo and R. L. Taylor, "A return mapping algorithm for plane stress elastoplasticity," International Journal for Numerical Methods in Engineering, vol. 22, no. 3, pp. 649670, 1986. 
[18] B. Moran, M. Ortiz, and F. Shih, "Formulation of implicit finite element methods for multiplicative finite deformation plasticity," International Journal for Numerical Methods in Engineering, vol. 29, no. 3, pp. 483-514, 1990.

[19] A. Saad, S. Guédon, and F. Martineau, "Alteration microstructurale de roches sedimentaires par des cycles de gel- degel : etude experimentale de parametres d'etat et de transfert," Comptes Rendus Geoscience, vol. 342, no. 3, pp. 197-203, 2010.

[20] N. Matsuoka, "Mechanisms of rock breakdown by frost action: an experimental approach," Cold Regions Science and Technology, vol. 17, no. 3, pp. 253-270, 1990.

[21] M. Mutluturk, R. Altindag, and G. Turk, "A decay function model for the integrity loss of rock when subjected to recurrent cycles of freezing-thawing and heating-cooling," International Journal of Rock Mechanics and Mining Sciences, vol. 41, no. 2, pp. 237-244, 2004.

[22] H. Yavuz, R. Altindag, S. Sarac, I. Ugur, and N. Sengun, "Estimating the index properties of deteriorated carbonate rocks due to freeze- thaw and thermal shock weathering," International Journal of Rock Mechanics and Mining Sciences, vol. 43, no. 5, pp. 767-775, 2006.

[23] M. Hori and H. Morihiro, "Micromechanical analysis on deterioration due to freezing and thawing in porous brittle materials," International Journal of Engineering Science, vol. 36, no. 4, pp. 511-522, 1998.

[24] R. K. Abu al-Rub and G. Z. Voyiadjis, "On the coupling of anisotropic damage and plasticity models for ductile materials," International Journal of Solids and Structures, vol. 40, no. 11, pp. 2611-2643, 2003.

[25] K. Maleki and A. Pouya, "Numerical simulation of damagepermeability relationship in brittle geomaterials," Computers and Geotechnics, vol. 37, no. 5, pp. 619-628, 2010.

[26] G. P. Davidson and J. F. Nye, "A photoelastic study of ice pressure in rock cracks," Cold Regions Science and Technology, vol. 11, no. 2, pp. 141-153, 1985.

[27] G. R. Irwin, J. A. Kies, and H. L. Smith, "Fracture strengths relative to onset and arrest of crack propagation," ProceedingsAmerican society for testing and materials, vol. 58, pp. 640660, 1958.

[28] J. Walder and B. Hallet, "A theoretical model of the fracture of rock during freezing," Geological society of America Bulletin, vol. 96, no. 3, pp. 336-346, 1985.

[29] M. Mikkola and J. Hartikainen, "Computational aspects of soil freezing problem," in In Fifth World Congress on Computational Mechanics, Vienna, Austria, 2002.

[30] S. W. Yu and X. Q. Feng, "A micromechanics-based damage model for microcrack-weakened brittle solids," Mechanics of Materials, vol. 20, no. 1, pp. 59-76, 1995.

[31] M. F. Ashby and S. D. Hallam, "The failure of brittle solids containing small cracks under compressive stress states," Acta Metallurgica, vol. 34, no. 3, pp. 497-510, 1986.

[32] H. Martin and Sadd, "Elasticity," in Theory, Application, and Numerics, Academic Press, 2005.

[33] H. Horii and S. Nemat-Nasser, "Compression-induced microcrack growth in brittle solids: axial splitting and shear failure," Journal of Geophysical Research, vol. 90, no. B4, pp. 31053125, 1985.

[34] S. Li and E. Z. Lajtai, "Modeling the stress-strain diagram for brittle rock loaded in compression," Mechanics of Materials, vol. 30, no. 3, pp. 243-251, 1998.
[35] R. I. Borja, K. M. Sama, and P. F. Sanz, "On the numerical integration of three-invariant elastoplastic constitutive models," Computer Methods in Applied Mechanics and Engineering, vol. 192, no. 9-10, pp. 1227-1258, 2003.

[36] X. J. Tan, W. Chen, J. Yang, and J. Cao, "Laboratory investigations on the mechanical properties degradation of granite under freeze-thaw cycles," Cold Regions Science and Technology, vol. 68, no. 3, pp. 130-138, 2011.

[37] C. Arson and J. M. Pereira, "Influence of damage on pore size distribution and permeability of rocks," International Journal for Numerical and Analytical Methods in Geomechanics, vol. 37, no. 8, pp. 810-831, 2013.

[38] F. S. Rostásy, R. Weib, and G. Wiedemann, "Changes of pore structure of cement mortars due to temperature," Cement and Concrete Research, vol. 10, no. 2, pp. 157-164, 1980. 